\title{
Voronoi Diyagramı ve Taksi Düzlemi Uzerine
}

\author{
Ziya AKÇA ${ }^{\mathrm{a}^{*}} \mathbb{D}$, Ceyda ÇALIŞ ${ }^{\mathrm{b}}(\mathbb{D}$ \\ aEskişehir Osmangazi Üniversitesi, Fen Edebiyat Fakültesi, Matematik-Bilgisayar Bölümü \\ Eskişehir- Türkiye

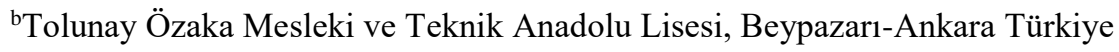

Geliş / Received: 05/03/2020, Kabul / Accepted: 09/03/2021

$\ddot{O} \mathbf{z}$

Bu çalışmada, Voronoi diyagramları, Fortune Algoritması ve Taksi düzlemde Voronoi diyagramları incelenmiştir.

Anahtar Kelimeler: Voronoi diagramları, Taksi düzlem geometri, Fortune algoritması

\section{On The Voronoi Diagram and Taxicab Plane}

\begin{abstract}
In this work, Voronoi diagrams, Fortune algorithm and Voronoi diagrams in the Taxicab plane are investigated.
\end{abstract}

Keywords: Voronoi diagrams, Taxicab geomtry, Fortune algorithm.

\section{Giriş}

Voronoi diyagramı 1903 yllında George Voronoi tarafindan karar uzayını oluşturan verilerin "mozaiklere bölünmesi" olarak tanımlanan veri parçalama yöntemidir. Düzlemde $\mathrm{n}$ farklı noktaya sahip bir P kümesi ele alındığında bu kümede yer alan herhangi bir noktaya kümedeki diğer noktalardan daha yakın bulunan noktaların geometrik yerine $o$ noktanın "Voronoi Çokgeni" denir. $P$ kümesindeki tüm noktaların Voronoi çokgenlerinin birleşimi ile o kümenin Voronoi diyagramı oluşur. $\mathrm{Bu}$ diyagram en yakın nokta problemlerinin çözümü için kullanılan bir yapıdır. Voronoi diyagramı hesaplamalarında genellikle Öklidyen düzlemdeki uzaklık fonksiyonları kullanılmaktadır.

Birçok matematik çalışmasında olduğu gibi Voronoi diyagramlarının da oldukça geniş uygulama sahası vardır. Genellikle astronomide gezegen yüzeylerinin incelenmesinde, coğrafya ve arkeolojide bölgedeki suyun akışının bölge topografyası üzerine etkisinin incelenmesinde, yol güzergâhlarının planlanmasında, biyolojide bazı bitkilerin yapısında, zürafanın vücut desenlerinde ve sanatsal ürünlerde Voronoi diyagramı ile karşılaşımaktadır. 
Örneğin, birçok marketin yer aldı $\breve{g}_{1}$ bir semtte büyük bir market zinciri bir şubesini açmak isterse bu marketin açılacağ 1 yer için yapılan araştırmalarda en fazla kazanç sağlayacak bölgenin belirlenmesi gerekmektedir. $\mathrm{Bu}$ semt için nüfusun düzgün dağılımlı olduğunu kabul ederek marketin açılacağı yerin doğru belirlenmesi gerekmektedir. Çünkü hiç bir yatırım rastgele yapılamaz. Dolayısıyla yeni açılacak marketin eski marketlerden oldukça uzağa konumlandırılması gerekmektedir. Bunun için açılacak market için seçilecek bölge, merkezi bu market olan ve içerisinde başka market bulunmayan en büyük çember bölgesi seçilir.

Yani en yakın diğer markete olan uzaklık çemberin yarıçapı kadar olmalıdır.

Şimdi Voronoi diyagramı ile ilgili bazı temel kavramları verelim (Fortune, 1987; Horn ve Weber, 2004; Miu, 2001; Özbek, 2010; Toma, 2010; Vassilev ve Eades, 2013).

$P=\left\{p_{1}, p_{2}, \ldots, p_{n}\right\} \quad$ Öklidyen düzlemde noktalar kümesi olsun. Düzlemdeki $p_{i}$ noktaları ve herhangi bir $q$ noktası için

$d_{E}\left(q, p_{i}\right)<d_{E}\left(q, p_{j}\right), p_{j} \in P, i \neq j$

koşulunu sağlıyorsa $q$ noktası $p_{i}$ hücresi içindedir denir ve bu yap 1. dereceden Voroni Diyagramı olarak adlandırılır. $P$ nin Voronoi diyagramı $\operatorname{Vor}(P)$ ile gösterilir.

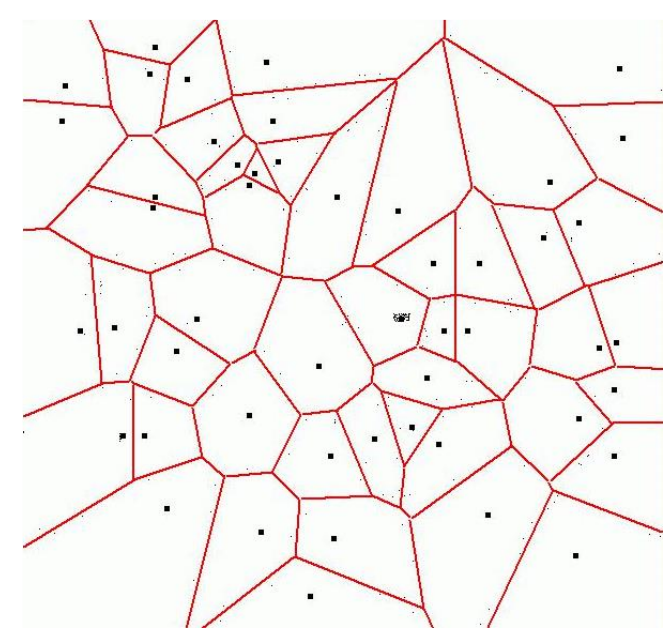

\section{Voronoi Kenarı}

Öklidyen düzlemde verilen noktalar kümesi $P=\left\{p_{1}, p_{2}, \ldots, p_{n}\right\}$ olsun. Her Voroni kenarı herhangi iki noktaya en yakın ve eşit uzaklıktaki noktaların kümesinden oluşur. Her Voronoi kenarı $\operatorname{Vor}\left(p_{i}\right)$ ve $\operatorname{Vor}\left(p_{j}\right)$ Voronoi hücrelerini sınırlar. Aynı zamanda Voronoi kenarı $p_{i}$ ve $p_{j}$ yi birleştiren doğru parçasının orta dikmesi üzerinde bulunmaktadir.

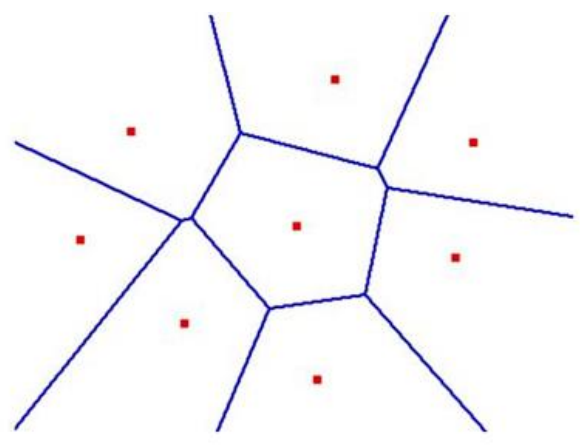

\section{Voronoi Köşesi}

$P=\left\{p_{1}, p_{2}, \ldots, p_{n}\right\} \quad$ noktalar kümesi verilsin.

Bu kümeden herhangi dördü dairesel olmayan noktalar ele alındığında bunlardan herhangi üç noktadan geçen en büyük çemberin merkezi bir Voronoi köşesidir. Eğer üçten fazla nokta dairesel ise oluşan çemberin 
kirişlerinin orta dikmelerinin arakesit noktası ile bir tane Voronoi köşe bulunur.

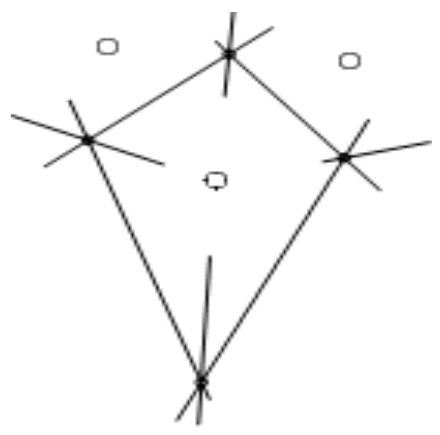

\section{Voronoi Hücresi}

Öklidyen düzlemde $P=\left\{p_{1}, p_{2}, \ldots, p_{n}\right\}$ seçilen noktalar kümesi olsun. Herhangi bir $p_{j}$ noktasını üzerinde bulunduran, Voronoi kenarları ile sınırlı ya da sınırsız alt bölgelere Voronoi hücresi denir. Hücrelerinin birleşmesi ile Voronoi diyagramı oluşur. Yani Öklidyen düzlemde noktalar kümesi $P=\left\{p_{1}, p_{2}, \ldots, p_{n}\right\} \quad$ iken bu kümedeki herhangi iki eleman birbirine en yakın olacak şekilde düzlemin parçalanması ile Voronoi diyagramı oluşturulur.

\section{Fortune algoritması}

Fortune algoritması, düzlemdeki noktalar kümesinden Voronoi diyagramının oluşturulmasında kullanılan bir düzlem tarama algoritmasıdır. Algoritma ilk olarak Steven Fortune tarafindan "A Sweepline Algorithm For Voronoi Diagrams" başlıklı çalışmasıyla yayınlanmıştır (Fortune, 1987). Algoritma bir tarama çizgisi bir de kıyı çizgisinden oluşur. $\mathrm{Bu}$ çizgiler algoritmanın işlemi sırasında düzlem boyunca hareket eder.

Fortune algoritmasında bir noktanın Voronoi diyagramını hesaplamak için tarama çizgisi kullanılır. Bu çizgi düz bir çizgidir ve klasik olarak düzlemde soldan sağa veya yukarıdan aşağıya doğru hareket eden bir çizgi olarak düşünülebilir. Dikey (veya yatay) çizgi düzlemi süpürür. Süpürme sırasında, nokta olayları ve çember olayları ile karşılaşıl- dığında gerekli olay işleyiciyi harekete geçirir.

Aslında bir $p$ noktasına ve bir 1 çizgisine eşit mesafedeki noktaların geometrik yeri, odağ $1 p$ ve doğrultmanı 1 olan bir paraboldür. Başlangıçta parabolün genişliği sıfırdır. Bu ise 1 ye dik bir 1şındır. Tarama çizgisi ilerledikçe parabolün genişliği artar ve diğer noktalar ile kesişir. Parabollerin kesiştikleri noktalara kırılma (kesme) noktaları denir. Voronoi diyagramlarının kenarları bu noktadan geçen doğrulardır.

Kıyı çizgisi ise tarama çizgisinin üstünde birçok parabolden oluşan karmaşık bir eğridir. Tarama çizgisinin üstündeki her nokta için bir parabol oluşur. Kırılma noktalarında kesişen bu parabolik yayların birleşimi kıyı çizgisini oluşturur.

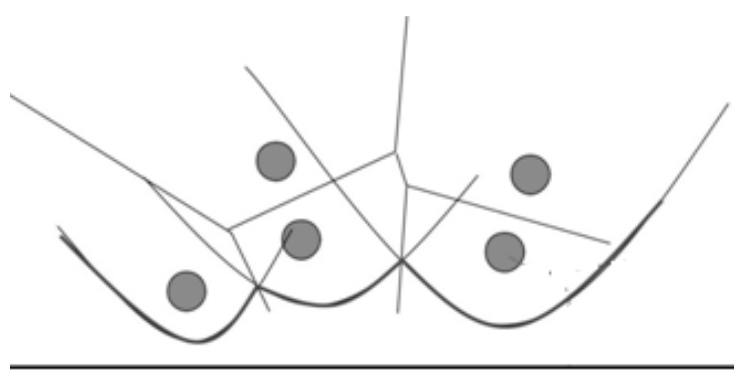

Taksi geometride trigonometrik fonksiyonlar, taksi çemberleriyle ilgili özellikler, küre üzerinde taksi uzaklık, dönmeler altında taksi uzaklık, koniklerin sinıflandırılması gibi çalışmalar (Akça ve Kaya, 1997; Bayar ve Ekmekçi, 2015; Bayar ve Kaya, 2005; Çalış, 2019; Ekici vd., 1998; Ekmekçi, 2001; Kaya vd., 2000; Özcan vd., 2002) de yapılmıştır.

Aşağıdaki bölümde taksi düzlemde bazı temel kavramlar verildikten sonra taksi düzlemde Fortune algoritması, taksi düzlemde taksi parabolleri yardımıyla kıyı çizgisi ve tarama çizgisi kullanılarak bir taksi Voronoi diyagramı örneği verilecektir. 


\section{Taksi Düzlemde Voronoi Diyagramı}

Taksi düzlemde noktalar, doğrular ve açı ölçülmesi Öklidyen düzlemdeki ile aynıdır. Taksi düzlem geometri kenar - açı - kenar özelliğini sağlamadığından Öklidyen olmayan bir geometridir. Dolayısıyla uzaklık fonksiyonları bu iki geometriyi birbirinden ayırır. Düzlemde verilen $A=\left(x_{1} y_{1}\right)$ ve $B=\left(x_{2} y_{2}\right)$ noktaları için $A$ ve $B$ noktaları arasındaki Öklidyen uzaklık

$$
d_{E}\left(A, B=\sqrt{\left(x_{2}-x_{1}\right)^{2}+\left(y_{2}-y_{1}\right)^{2}}\right.
$$

iken $A$ ve $B$ noktaları arasındaki taksi uzaklık

$$
d_{T}(A, B)=\left|x_{2}-x_{1}\right|+\left|y_{2}-y_{1}\right|
$$

şeklinde tanımlıdır.

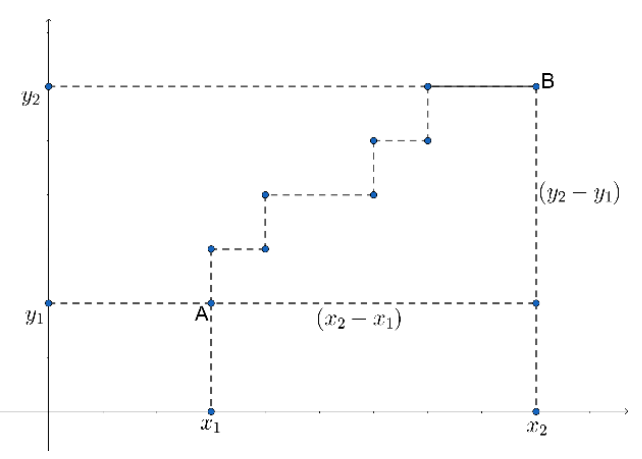

\section{Taksi çemberi}

Taksi düzlemde bulunan sabit bir noktadan sabit bir taksi uzaklığındaki noktaların geometrik yeri taksi çemberi olarak adlandırılır. Taksi düzlemindeki sabit nokta taksi çemberinin merkezini, sabit taksi uzaklı̆̆ da taksi çemberinin yarçcap uzunluğunu gösterir.
Analitik düzlemde merkezi $M=(a, b)$ ve yarıçapı $r$ olan taksi çemberi

$$
C=\{(x, y):|x-a|+|y-b|=r \text { ve } x, y \in R\}
$$

şeklinde tanımlıdır.

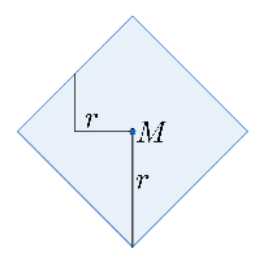

\section{Taksi Düzlemde Doğruların Sinıflandırılması}

Taksi düzlemde $l \ldots . . \mathrm{ax}+\mathrm{by}+\mathrm{c}=0 \quad$ doğrusu verilsin. $l$ doğrusuna,

i-) $\left|\frac{a}{b}\right|>1$ ise dikeysel doğru,

ii-) $\left|\frac{a}{b}\right|<1$ ise yataysal doğru,

iii-) $\left|\frac{a}{b}\right|=1 \quad$ ise ayıraç doğru

adı verilir.

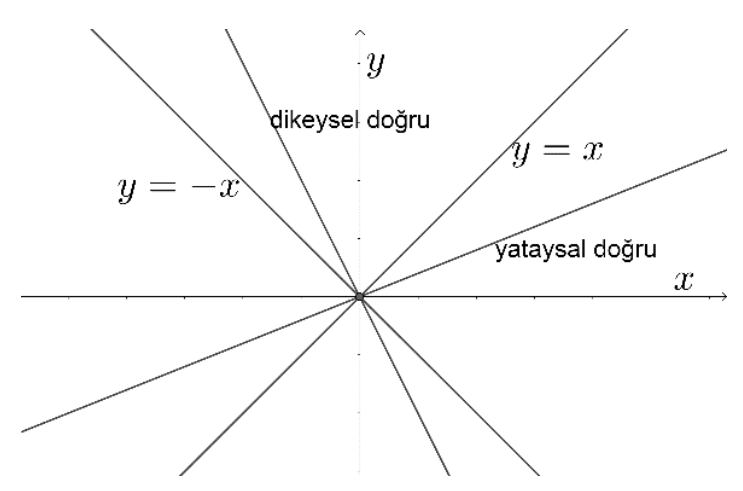


9. Taksi Düzlemde Bir Noktanın Doğruya Uzaklığı

Taksi düzlemde bir $P$ noktasının bir $l$ doğrusuna uzaklığı, $P$ nin $l$ doğrusu üzerindeki noktalara uzaklıklarından en küçüğü olarak tanımlanır.

$\mathrm{Bu} \quad$ uzaklık $\quad d_{T}(P, l)=\min _{X \in l}\left\{d_{T}(X, P)\right\}$ şeklindedir.

10. Taksi Düzlemde En Kısa Uzaklık Kümesi

Taksi düzlemde herhangi $A$ ve $B$ noktaları için

$d_{T}(A, B)=d_{T}(A, X)+d_{T}(X, B)$

özelliğindeki tüm $X$ noktalarının kümesine en kısa uzaklık kümesi denir.

\section{Taksi Düzlemde Orta Küme}

Taksi düzlemde herhangi $A$ ve $B$ noktalarına eşit taksi uzaklıktaki noktaların geometrik yerine $A$ ve $B$ noktalarının orta kümesi denir. Bu küme

$$
\left\{P=(x, y): d_{T}(P, A)=d_{T}(P, B), x, y \in R\right\}
$$

şeklinde tanımlıdır.

$\mathrm{Bu}$ bölümde taksi düzleminde taksi parabolleri ve taksi orta kümeleri kullanılarak bir taksi Voronoi diyagramı örneği verilecektir.

Örnek: Taksi düzlemde odak noktaları
$A=(0,4), B=(-4,0)$ ve $C=(4,0)$ ve doğrultman 1 $\mathrm{y}=-2$ olan taksi parabollerinin denklemleri belirlenerek taksi parabolleri çizilir ve kıyı çizgisi oluşturulurak taksi Voronoi diyagramı oluşturulur. Bunun için;

1) Odak noktası $A=(0,4)$ ve doğrultmanı $y=-2$ olan taksi parabol denklemi

$$
|x|+|y-4|=|y+2|
$$

dir. Bu denklemin çözümünden

$x \geq 0$ ve $y \geq 4$ için $x=6$ doğru parçası,

$x \geq 0$ ve $0 \leq y \leq 4$ için $x-2 y=-2$ doğru parçası,

$$
\begin{aligned}
& x \leq 0 \text { ve } y \geq 4 \text { için } x=-6 \text { doğru parçası, } \\
& x \leq 0 \text { ve } 0 \leq y \leq 4 \text { için }-x-2 y=-2 \text { doğru }
\end{aligned}
$$
parçası elde edilir.

2) Odak noktası $B=(-4,0)$ ve doğrultmanı

$y=-2$ olan taksi parabol denklemi

$$
|x+4|+|y|=|y+2|
$$

dir. Bu denklemin çözümünden

$$
x \geq-4 \text { ve } y \geq 0 \text { için } x=-2 \text { doğru parçası, }
$$

$x \geq-4$ ve $-2 \leq y \leq 0$ için $x-2 y=-2$ doğru parçası,

$x \leq-4$ ve $y \geq 0$ için $x=-6$ doğru parçası,

$x \leq-4$ ve $-2 \leq y \leq 0$ için $-x-2 y=6$ doğru parçası elde edilir. 
3) Odak noktası $C=(4,0)$ ve doğrultmanı $y=-2$ olan taksi parabol denklemi

$$
|x-4|+|y|=|y+2|
$$

dir. Bu denklemin çözümünden

$$
\begin{aligned}
& x \geq 4 \text { ve } y \geq 0 \text { için } x=6 \text { doğru parçası, } \\
& \quad x \geq 4 \text { ve }-2 \leq y \leq 0 \text { için } x-2 y=6 \text { doğru } \\
& \text { parçası }
\end{aligned}
$$

$x \leq-4$ ve $y \geq 0$ için $x=2$ doğru parçası,

$x \leq-4$ ve $-2 \leq y \leq 0$ için $-x-2 y=-2$ doğru parçası elde edilir.

Dolayısıyla bu denklemlerle oluşan taksi düzlemde odak noktaları $A, B, C$ noktaları ve doğrultmanı $y=-2$ olan taksi parabolleri çizilip kırılma noktalarında kesişen bu taksi parabollerinin birleşimi taksi kıyı çizgisini oluşturur ve oluşan taksi kıyı çizgisi aşağıdaki gibidir.

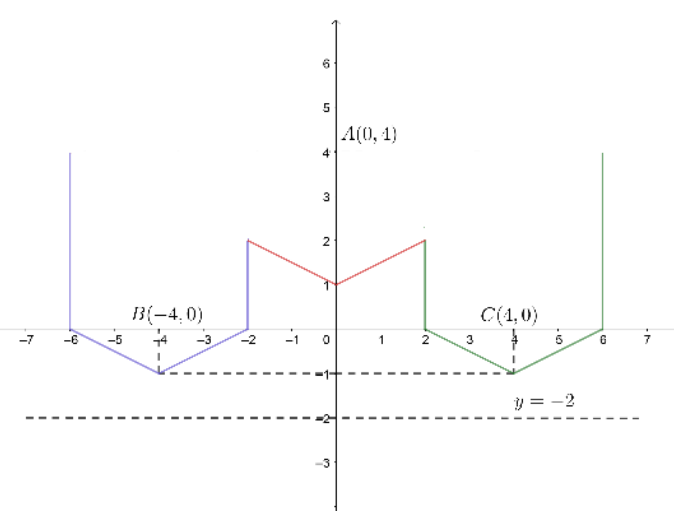

Tarama çizgisi iki birim aşağı kaydırıldığında taksi kıyı çizgisinin ve taksi parabollerinin durumlarını incelenirse.
O zaman doğrultmanı $y=-4$ doğrusu olmak üzere odak noktaları

$A=(0,4), B=(-4,0)$ ve $C=(4,0)$ olan taksi parabollerinin denklemleri sırasıyla,

$|x|+|y-4|=|y+4|, \quad|x+4|+|y|=|y+4|$ ve

$|x-4|+|y|=|y+4| \quad$ dir. $\quad \mathrm{Bu} \quad$ denklemlerin çözümünden

$x= \pm 8, x=0, x= \pm 2 y,-x-2 y=8$ ve $x-2 y=8$ doğru parçalarından oluşan taksi parabollerinin arakesit noktası $K=(0,0)$ noktasıdır. Tarama çizgisi aşağı doğru hareket ettirildiğinde kenardaki taksi paraboller ortada bulunan parabol üzerine genişleyerek bir noktada kesişirler. Dolayısıyla $K=(0,0)$ kesişim noktası $A, B, C$ noktalarından geçen taksi çemberin merkezidir ve bir taksi köşe noktasıdır.

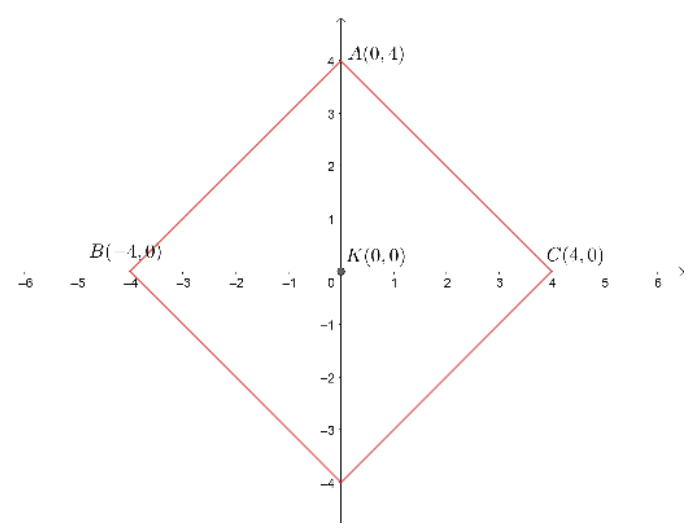

Dolayısıyla oluşan taksi kıyı çizgisi aşağıdaki gibidir. 


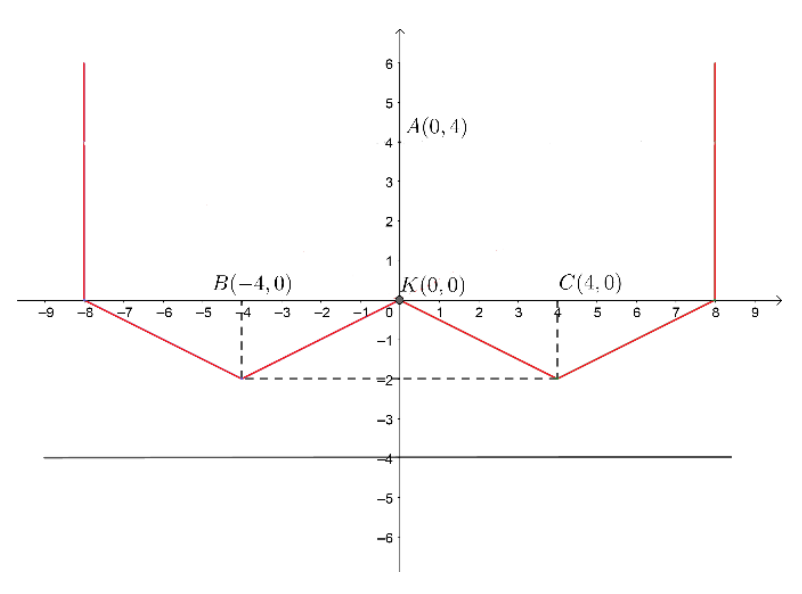

Kaya R., Akça Z., Özcan M., Günaltılı İ. 2000. "General Equation for Taxicab Conics and Their Classification", Mitt. Math. Ges. Hamburg , 19(0), 135-148.

Miu A. 2001. "Computatonal Geometry, Lecture 7: Voronoi Diagrams", nms.csail.mit.edu/ aklmiu/6.838/L7.pdf, 25.03.2021.

Özcan M., Ekmekçi S., Bayar A. 2002. "The

\section{Kaynaklar}

Akça Z., Kaya R. 1997. "On the Taxicab Trigonometry”, J. of Inst. Math. Comput. Sci. Math. Ser., 10, 151-159.

Bayar A., Ekmekçi, S. 2015. "On Complex Numbers and Taxicab Plane", Mathematical Sciences \& Applications E-Notes, 3(1), 58-64.

Bayar A., Kaya R. 2005. "On the Taxicab Distance on a Sphere", Missouri Journal of Mathematical Sciences, 41-51.

Çalış C. 2019. "Taksi Düzlemde Voronoi Diyagramları Üzerine", Yüksek Lisans, Eskişehir Osmangazi Üniversitesi Fen Bilimleri Enstitüsü, 1-60.

Ekici C., Kocayusufoğlu İ., Akça Z. 1998. "The Norm in Taxicab Geometry", Turkish J. Math., 22(3), 295-307.

Ekmekçi, S. 2001. "Taksi Çemberleriyle İlgili Özellikler”, Doktora, Eskişehir Osmangazi Üniversitesi Fen Bilimleri Enstitüsü, 5-11.

Fortune S. 1987. "A Sweepline Algorithm for Voronoi Diagrams”, Algorithmica, 2, 153174.

Horn, M., Weber J. 2004. "Computational Geometry Lecture Notes Voronoi Diagrams", URL: www.cs.princeton.edu > courses > archive > spring12 > cos423 > bib > vor, 25.03.2021.
Taxicab Lengths under Rotations", The Pi Mu Epsilon Journal, 381-384.

Özbek B. 2010. “İki ve Üç Boyutlu Cisimlerin Voronoi Diyagramlarının Çıkarılması ve Delaunay Mozaiklemesinin Gerçekleştirilmesi”, Yüksek Lisans, Ankara Üniversitesi Fen Bilimleri Enstitüsü, 1-102.

Toma L. 2010. "Computational Geometry", Bowdin College, 1-112.

Vassilev S., Eades B. 2013. "Generalions of the Voronoi Diagram", American Journal of Computational and Applied Mathematics, 9196. 